\title{
Validation of a Three-Dimensional Ablation and Thermal Response Simulation Code
}

\author{
Y.-K. Chen ${ }^{*}$ and F.S. Milos ${ }^{\dagger}$ \\ NASA Ames Research Center, Moffett Field, CA 940350-1000 \\ Tahir Gökçen ${ }^{\star}$ \\ ELORET Corporation, Sunnyvale, CA 94086
}

The 3dFIAT code simulates pyrolysis, ablation, and shape change of thermal protection materials and systems in three dimensions. The governing equations, which include energy conservation, a three-component decomposition model, and a surface energy balance, are solved with a moving grid system to simulate the shape change due to surface recession. This work is the first part of a code validation study for new capabilities that were added to 3dFIAT. These expanded capabilities include a multi-block moving grid system and an orthotropic thermal conductivity model. This paper focuses on conditions with minimal shape change in which the fluid/solid coupling is not necessary. Two groups of test cases of 3dFIAT analyses of Phenolic Impregnated Carbon Ablator in an arc-jet are presented. In the first group, axisymmetric iso-q shaped models are studied to check the accuracy of threedimensional multi-block grid system. In the second group, similar models with various through-the-thickness conductivity directions are examined. In this group, the material thermal response is three-dimensional, because of the carbon fiber orientation. Predictions from 3dFIAT are presented and compared with arcjet test data. The 3dFIAT predictions agree very well with thermocouple data for both groups of test cases.

\section{Nomenclature}

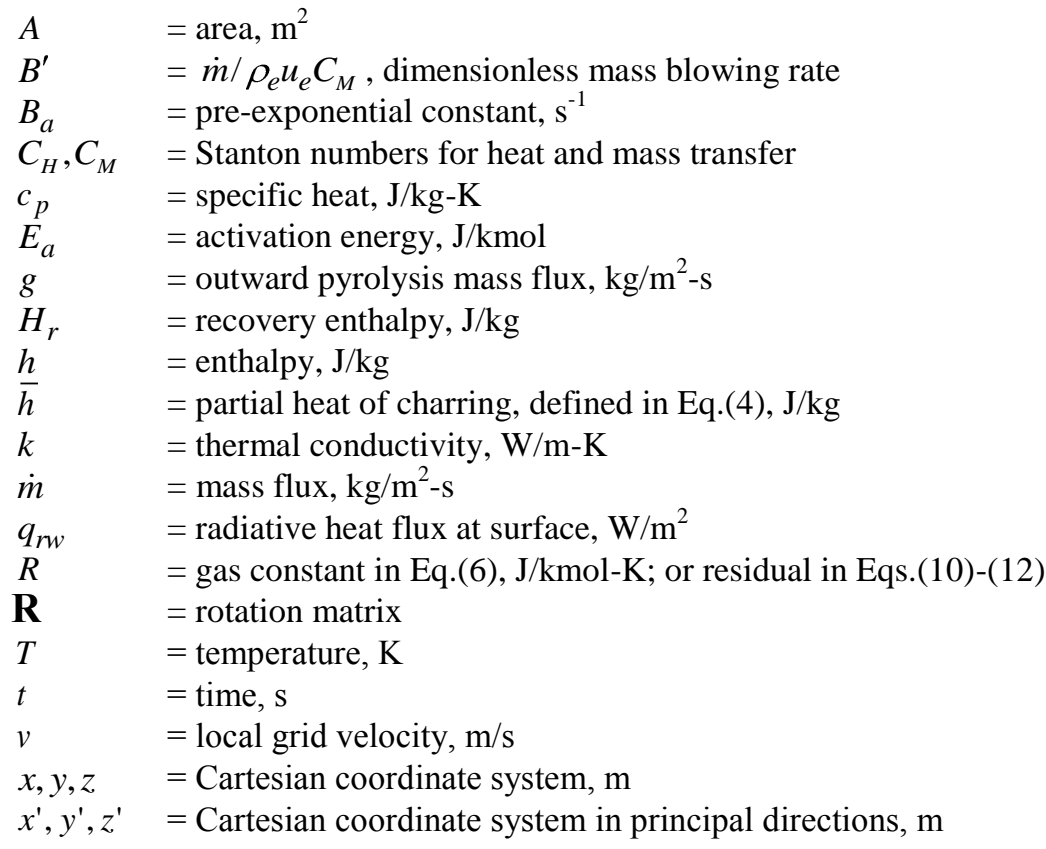

\footnotetext{
* Aerospace Engineer, Aerothermodynamics Branch, MS 230-2, Member AIAA.

${ }^{\dagger}$ Aerospace Engineer, Thermal Protection Materials Branch, MS 234-1. Senior Member AIAA.

* Senior Research Scientist, Senior Member AIAA.
} 


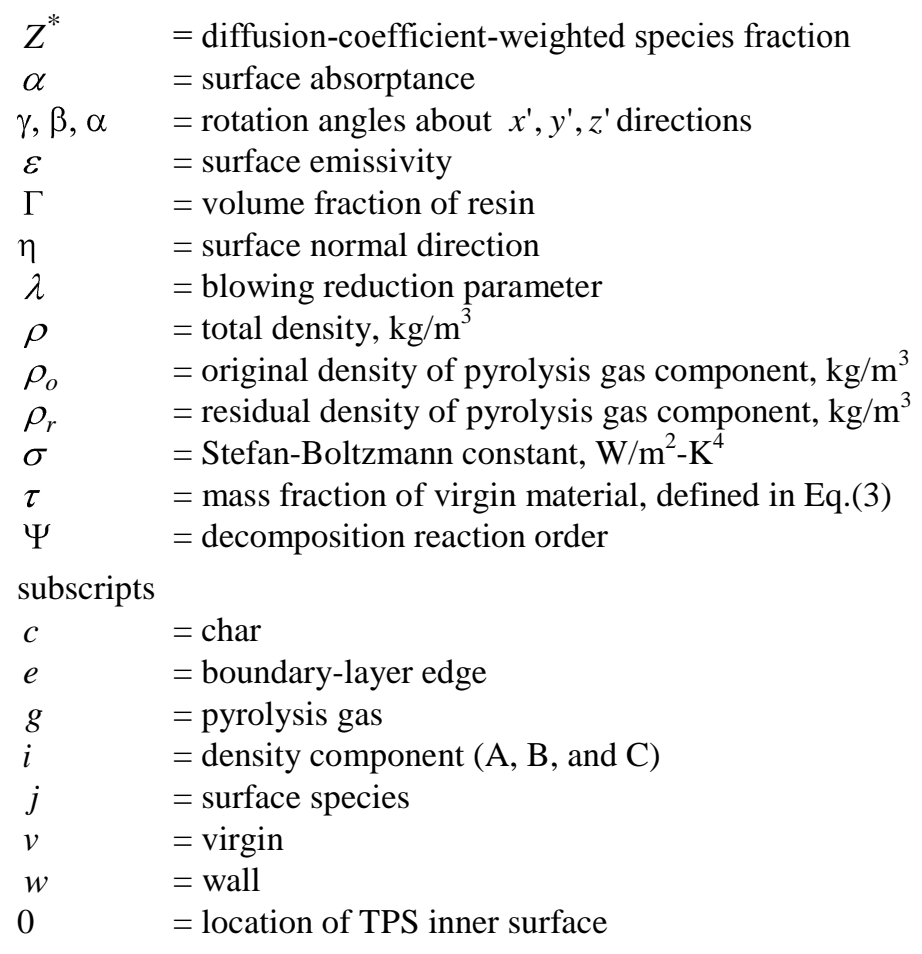

\section{Introduction}

The authors have developed a family of programs for analysis of ablative thermal protection system (TPS) materials. Fully Implicit Ablation and Thermal response code (FIAT), Two-dimensional Implicit Thermal response and $\underline{\text { Ablation }}$ code (TITAN), and $\underline{3}$-dimensional Finite-volume alternatively directional Implicit $\underline{\text { Ablation }}$ and Thermal response code (3dFIAT) simulate the internal heat conduction, in-depth thermal decomposition, quasisteady pyrolysis gas flow, and surface ablation of TPS materials in one, two, and three dimensions, respectively. ${ }^{1-3}$ FIAT is widely used by NASA and industry as the one-dimensional analysis and sizing tool for spacecraft TPS materials. TITAN can analyze problems with two-dimensional or axisymmetric geometry. In some cases, a twodimensional analysis is inadequate, and a three-dimensional ablation code is required to perform a high fidelity simulation. The 3dFIAT program can analyze the thermal response of the entire heatshield of a space vehicle. The prediction of ablative heatshield response for a spacecraft entering the atmosphere with an angle of attack is such a case. The first version of 3dFIAT was a single-block finite-volume program, and it was not sufficiently flexible to model a complicated TPS/structure with multiple materials. However, by integrating 3dFIAT and MARC, ${ }^{4}$ a simulation system was developed. This system can predict surface recession, shape change, in-depth pyrolysis, and internal thermal response for a three-dimensional TPS/structure system under general hypersonic entry conditions.

The purposes of this paper are to demonstrate and validate the new capabilities that were added to the 3dFIAT program specifically for analysis of TPS materials. These expanded capabilities include a multiple-block moving grid system and a model for orthotropic thermal conductivity. A multiple-block system allows 3dFIAT to perform computations for some TPS/structure systems with complicated geometry and multiple materials without integrating with MARC. The properties of many thermal protection materials are transverse isotropic, which is a subset of orthotropic. For transverse isotropic materials, depending on fiber orientation, there is a primary "through-thethickness" (TTT) direction with thermal conductivity that is different (and typically lower) from the value in the perpendicular plane (call the IP direction). The fibers are in the IP direction. Phenolic Impregnated Carbon Ablator (PICA) is one example of an orthotropic material. ${ }^{5}$

This is the first part of 3dFIAT validation effort. The results presented in this paper focus on conditions with surface recession but without significant shape change, such that the fluid/solid shape change coupling is not necessary. Conditions that require fluid/solid coupling will be discussed in a separate paper. Here, two groups of test cases of 3dFIAT analyses of PICA in an arc-jet are considered. In the first group, an axisymmetric iso-q shaped model is studied to check the accuracy of the three-dimensional multi-block moving grid system. In the second group, similar models with various TTT conductivity directions are examined. In this group, the material thermal 
response is three-dimensional even if the surface geometry is symmetric, because of the carbon fiber orientation. For both groups, the predicted in-depth temperature histories are compared with available thermocouple data.

\section{Governing Equations}

The internal energy balance ${ }^{3}$ is a transient thermal conduction equation with additional pyrolysis terms:

$$
\rho c_{p} \frac{\partial T}{\partial t}=\nabla \cdot(k \nabla T)-\left(h_{g}-\bar{h}\right) \nabla \cdot \dot{m}_{g}-\dot{m}_{g} \cdot \nabla h_{g}+\rho c_{p} v \cdot \nabla T
$$

The individual terms in Eq.(1) are interpreted as follows: rate of storage of sensible energy, net rate of thermal conductive heat flux, pyrolysis energy-consumption rate, net rate of energy convected by pyrolysis, and convection rate of sensible energy due to coordinate system movement.

The specific heat is input as a function of temperature for both virgin and fully-charred material. In partially pyrolyzed zones $\left(\rho_{c}<\rho<\rho_{v}\right)$, the specific heat is obtained from the mixing rule

$$
c_{p}=\tau c_{p v}+(1-\tau) c_{p c}
$$

where

$$
\tau=\frac{\rho_{v}}{\rho_{v}-\rho_{c}}\left(1-\frac{\rho_{c}}{\rho}\right)
$$

The weighting variable $\tau$ is the mass fraction of virgin material, in a hypothetical mixture of virgin material and char, which yields the correct local density. The thermal conductivity, $k$, is weighted in a similar manner as $c_{p}$.

The pyrolysis gas enthalpy, $h_{g}$, is input as a function of temperature and pressure. The quantity $\bar{h}$ in Eq.(1), as defined below, is a function of temperature and is calculated from other input quantities.

$$
\bar{h}=\frac{\rho_{v} h_{v}-\rho_{c} h_{c}}{\rho_{v}-\rho_{c}}
$$

Thermal and mechanical properties, including $c_{p}$ and $k$ of virgin and char of many spacecraft heatshield materials, are available in the TPSX material properties database, accessible through the Internet. ${ }^{6}$

For pyrolyzing TPS materials, a standard three-component decomposition model is used. ${ }^{7}$ The resin filler consists of two components $\mathrm{A}$ and $\mathrm{B}$, and the reinforcing material $\mathrm{C}$ is the third component. The instantaneous local density of the composite is given by

$$
\rho=\Gamma\left(\rho_{A}+\rho_{B}\right)+(1-\Gamma) \rho_{C}
$$

where the parameter $\Gamma$ is the volume fraction of resin and is an input quantity. The three components decompose independently following the relation

$$
\frac{\partial \rho_{i}}{\partial t}=-B_{a i} \exp \left(\frac{-E_{a i}}{R T}\right) \rho_{o i}\left(\frac{\rho_{i}-\rho_{r i}}{\rho_{o i}}\right)^{\Psi_{i}}+v \cdot \nabla \rho_{i}
$$

where $\rho_{r i}$ is the residual or terminal density of component $i$, and $\rho_{o i}$ is the original density of component $i$.

The motion of pyrolysis gas is assumed to be one-dimensional (in the surface-normal direction $\eta$ ) and quasisteady. Thus the mass flow rate of pyrolysis gas at the surface is calculated as 


$$
\dot{m}_{g}=\frac{-1}{A_{w}} \int_{7_{0}}^{\eta_{w}}\left(\frac{\partial \rho}{\partial t}\right) A_{\eta} d \eta
$$

where $\eta_{0}$ is located at the inner surface of the TPS.

\section{Boundary Conditions}

Conditions at the ablating surface are determined by convective and radiative heating and by surface thermochemical interactions with boundary-layer gases. The surface energy balance equation is written in general convective transfer-coefficient form as follows: ${ }^{7}$

$$
\rho_{e} u_{e} C_{H}\left(H_{r}-h_{e w}\right)+\rho_{e} u_{e} C_{M}\left[\sum\left(Z_{j e}^{*}-Z_{j w}^{*}\right) h_{j}^{T_{w}}-B^{\prime} h_{w}\right]+\dot{m}_{c} h_{c}+\dot{m}_{g} h_{g}+\alpha_{w} q_{r w}-\sigma \varepsilon_{w} T_{w}^{4}-q_{c w}=0
$$

The first term in Eq. (8) represents the sensible convective heat flux, where $h_{e w}$ is the enthalpy of edge gas with frozen composition at the wall temperature. The sum of the second, third, and fourth terms in Eq. (8) is defined as the total chemical energy at the surface. The term containing $Z^{*}$ represents the transport of chemical energy associated with chemical reactions at the wall and in the boundary layer. The $Z^{*}$ driving forces for diffusive mass transfer include the effects of unequal diffusion coefficients. The fifth and sixth terms are the radiative heat fluxes absorbed and re-radiated by the wall, respectively, and the last term, $q_{c w}$, represents the rate of heat conduction into the TPS. Here $B^{\prime}$ is the normalized mass blowing rate. The Aerotherm Chemical Equilibrium (ACE) ${ }^{8}$ or Multicomponent Ablation Thermochemistry (MAT) ${ }^{9}$ codes can be used to generate tables of $B^{\prime}$ for charring materials.

A blowing correction accounts for the reduction in transfer coefficients due to the transpiration of gases from pyrolysis and surface ablation into the boundary layer. The blowing rate correction equation for convective heat transfer is

$$
\frac{C_{H}}{C_{H 1}}=\frac{\ln \left(1+2 \lambda B^{\prime}\right)}{2 \lambda B^{\prime}}
$$

where $\lambda$ is the blowing reduction parameter, $C_{H}$ is the heat transfer coefficient for the ablating surface, and $C_{H 1}$ is the heat transfer coefficient for the non-ablating surface. With $\lambda=0.50$, Eq. (9) reduces to the classical blowing correction for laminar flow. ${ }^{10}$

The time dependent temperature and density boundary conditions at the interface of two blocks are estimated using a linear interpolation routine based on the value at the center of boundary cells.

\section{Orthotropic Thermal Conductivity}

For materials with orthotropic thermal conductivity, the thermal conductivities in three principle directions must be defined. The thermal conductivity of many thermal protection materials is transverse isotropic, which is a subset of orthotropic thermal conductivity. For transverse isotropic materials, there is a primary through-the-thickness (TTT) direction with thermal conductivity that is different (and often lower) than the value in the perpendicular plane (called the in-plane or IP direction). PICA is one example of a transverse isotropic material. To define a transverse isotropic material in 3dFIAT, the thermal conductivities in the principle orthogonal directions (TTT and IP) are input. For a general three-dimensional body rotation from the principle directions $\left(x^{\prime}, y^{\prime}, z^{\prime}\right)$ to the local Cartesian coordinates $(x, y, z)$, the rotation matrix $\mathbf{R}$ may be expressed in terms of three angles $(\gamma, \beta$, and $\alpha)$. $\gamma, \beta$, and $\alpha$ are the counterclockwise rotations about $x^{\prime}, y^{\prime}$, and z' axis, respectively. 


$$
\begin{aligned}
& \mathbf{R}=\mathbf{R}_{z^{\prime}}(\alpha) \mathbf{R}_{y^{\prime}}(\beta) \mathbf{R}_{x^{\prime}}(\gamma) \\
& \mathbf{R}_{z^{\prime}}(\alpha)=\left[\begin{array}{ccc}
\cos \alpha & -\sin \alpha & 0 \\
\sin \alpha & \cos \alpha & 0 \\
0 & 0 & 1
\end{array}\right] \\
& \mathbf{R}_{y^{\prime}}(\beta)=\left[\begin{array}{ccc}
\cos \beta & 0 & \sin \beta \\
0 & 1 & 0 \\
-\sin \beta & 0 & \cos \beta
\end{array}\right] \\
& \mathbf{R}_{x^{\prime}}(\gamma)=\left[\begin{array}{ccc}
1 & 0 & 0 \\
0 & \cos \gamma & -\sin \gamma \\
0 & \sin \gamma & \cos \gamma
\end{array}\right] \\
& \mathbf{R}=\left[\begin{array}{ccc}
\cos \alpha \cos \beta & \cos \alpha \sin \beta \sin \gamma-\sin \alpha \cos \gamma & \cos \alpha \sin \beta \cos \gamma+\sin \alpha \sin \gamma \\
\sin \alpha \cos \beta & \sin \alpha \sin \beta \sin \gamma+\cos \alpha \cos \gamma & \sin \alpha \sin \beta \cos \gamma-\cos \alpha \sin \gamma \\
-\sin \beta & \cos \beta \sin \gamma & \cos \beta \cos \gamma
\end{array}\right]
\end{aligned}
$$

and

$$
\left\lfloor\begin{array}{ccc}
K_{x x} & K_{x y} & K_{x z} \\
K_{y x} & K_{y y} & K_{y z} \\
K_{z x} & K_{z y} & K_{z z}
\end{array}\right]=\mathbf{R}^{\mathrm{T}}\left[\begin{array}{ccc}
K_{T T} & 0 & 0 \\
0 & K_{I P} & 0 \\
0 & 0 & K_{I P}
\end{array}\right] \mathbf{R}
$$

For typical arcjet models, we may set both $\gamma$ and $\beta$ equal to 0 , and $\alpha$ is the angle in the $x^{\prime}-y^{\prime}$ plane between the TTT direction (x') and the axis of symmetry (x). The rotation matrix, $\mathbf{R}$, becomes a single rotation about the z-axis, $\mathbf{R}_{\mathbf{z}}$. The local Cartesian coordinates and the principal directions of an isotropic transverse material used for the simulation of isq-q shaped arc-jet models are shown in Fig. 1. For baseline PICA material, the TTT direction is parallel to the axis of symmetry, and $\alpha$ is equal to $0^{\circ}$. Thus $K_{x x}=K_{T T}, K_{y y}=K_{z z}=K_{I P}$, and the rest of elements in conductivity tensor are zero.

\section{Test Cases}

The computations presented in this paper for 3dFIAT validation focus on analysis of iso-q shaped models typically used in the arc-jet testing conducted at NASA Ames Research Center. It has been shown in the previous work that shape change due to surface recession on an iso-q model is insignificant after its exposure to arc-jet stream. ${ }^{11}$ This is because the surface recession over the front surface of model is fairly uniform. Consequently, the heating and pressure profiles over the model surface remain unchanged during its exposure in the arc-jet stream. The material thermal response simulation of an iso-q shaped model can thus be performed without flow/solid shape change coupling.

There are two groups of cases studied in this work. The first group has arc-jet models with baseline PICA, which has the TTT direction aligned with the flow direction $\left(\alpha=0^{\circ}\right)$. In this group, the material thermal response is axisymmetric. The predictions using a three-dimensional multi-block moving grid system are compared with the available thermocouple data to check the accuracy of the grid system. The second group has models with somewhat different thickness profiles and $\alpha$ equal to $0^{\circ}, 45^{\circ}, 70^{\circ}$ and $90^{\circ}$. These cases are used to examine the orthotropic thermal conductivity model implemented in the code for three-dimensional thermal diffusion. The surface geometry of the test models is axisymmetric. However, the material thermal response is three-dimensional if $\alpha$ is non-zero. The predictions made in the second group are also compared with thermocouple data to study if the code is selfconsistent and accurate.

\section{A. Group I}

The material map for the arc-jet model studied in the first group is shown in Fig. 2. The geometry is an iso-qshaped PICA model with 10.16-cm diameter, and the model holder is made of LI-2200. The initial surface geometry 
of test model is axisymmetric. Figure 3 is the computational grid system generated for Group I simulation. We use a three-block no-singular-line grid system. The grid size is $70 \times 87 \times 19$ (block 1), $47 \times 155 \times 19$ (block 2 ), and $6 \times 132 \times 11$ (block 3). Based on our experience, computations using an axisymmetric three-dimensional grid system with a singular line may result in anomalous predictions around the singular line. The purpose of the third block of the grid is to avoid the presence of a singular line along the axis of symmetry.

Two test cases, G1a and G1b, are studied in the first group. The arc-jet exposure time, stagnation heat flux, and stagnation pressure for both cases are listed in Table I. The TTT direction (x') of PICA material is parallel to the arc flow direction $(\mathrm{x})$. This is called the baseline PICA configuration. The coordinate systems used in the baseline configuration are depicted in Fig. 4. The principle directions (x', y', z') of thermal conductivity tensor coincide with the directions of local coordinates $(\mathrm{x}, \mathrm{y}, \mathrm{z})$. Thus $\alpha$ is equal to $0^{\circ}$. The surface heating and pressure distributions, applied as the boundary conditions for 3dFIAT, are predicted by DPLR. ${ }^{12}$ As discussed earlier, these conditions are assumed to be independent of time during the exposure to arc stream, because shape change is negligibly small. The predicted heating and pressure profiles over the model surface for case G1a are shown in Fig.5.

Table I: Arc-jet conditions

\begin{tabular}{|c|c|c|c|}
\hline \hline Case & Exposure Time $(\mathrm{sec})$ & Heat Flux $\left(\mathrm{W} / \mathrm{cm}^{2}\right)$ & Pressure $(\mathrm{kPa})$ \\
\hline G1a & 42 & 246 & 8.5 \\
G1b & 60 & 169 & 5.0 \\
G2 & 45 & 768 & 46.7 \\
\hline \hline
\end{tabular}

The comparison of in-depth temperature history between thermocouple data and prediction by 3dFIAT for Case G1a is presented in Figs. 6a to 6c. The thermocouples, TC1 to TC6, are located at the centerline of iso-q model (radius $=0$ ) and at various depths. TC7, TC8, TC9, and TC10 are off the centerline (radius > 0). The location of each thermocouple is listed in Table II. "Depth" is the distance along the centerline from the initial stagnation point, and "Radius" is the distance to the centerline of model. The predictions (black lines) and the thermocouple data (red lines) are in excellent agreement for all the thermocouples. Similar comparisons for Case G1b are presented in Figs 7a to 7c. Again, the agreement between computation and data is good. This agreement indicates that the threedimensional multi-block no-singular-line grid system is correctly implemented in the $3 \mathrm{dFIAT}$ code. The stagnation point recession predicted by $3 \mathrm{dFIAT}$ is exactly the same as that by TITAN and FIAT, because the ablation models adopted in these three codes are identical. Thus, the comparison of predicted recession with data is not discussed here. The same computations performed by TITAN and FIAT can be found in Reference 5. Figure 8 shows the predicted temperature contours on the plane of symmetry ( $\mathrm{x}-\mathrm{y}$ plane) for Case G1a at time equal to 600 sec. As expected, the thermal response of the PICA model is axisymmetric.

Table II: The locations of thermocouples for Group I

\begin{tabular}{|c|c|c|}
\hline \hline Group I & Depth $(\mathrm{cm})$ & Radius $(\mathrm{cm})$ \\
\hline TC1 & 0.38 & 0 \\
TC2 & 0.76 & 0 \\
TC3 & 1.14 & 0 \\
TC4 & 1.52 & 0 \\
TC5 & 2.29 & 0 \\
TC6 & 3.05 & 0 \\
TC7 & 2.29 & 4.44 \\
TC8 & 2.29 & 3.81 \\
TC9 & 2.29 & 2.54 \\
TC10 & 3.05 & 4.44 \\
\hline \hline
\end{tabular}

\section{B. Group II}

The surface geometry of the arc-jet model for the second group is the same as that for the first group, but the thickness of the PICA material is different. The thickness of PICA along the centerline is $3.49 \mathrm{~cm}$ for this group, and it is $4.13 \mathrm{~cm}$ for the first group. The material map of Group II is shown in Fig. 9. The no-singular-line, three-block 
computational grid system is presented in Fig. 10. The grid block sizes are the same as those for Group I. In this group, the iso-q shaped PICA models with various TTT angles $\left(0^{\circ}, 45^{\circ}, 70^{\circ}\right.$, and $\left.90^{\circ}\right)$ are studied. The arc-jet stream conditions are listed at row $\mathrm{G} 2$ in Table I.

Figure 11 is the comparison of stagnation point total recession between 3dFIAT prediction and measured data. The predicted total recession $(1.2 \mathrm{~cm})$ is slightly lower than the measured value. The difference between prediction and data is less than 6\%. The comparison between thermocouple data (TC11 to TC15) and 3dFIAT predictions at TTT directions of $0^{\circ}, 45^{\circ}, 70^{\circ}$, and $90^{\circ}$ are presented in Figs. 12a to $12 \mathrm{~d}$, respectively. The locations of thermocouples are listed in Table III. Generally speaking, data and predictions are in good agreement for all the TTT directions. The only noticeable discrepancy between data and computation is at the location of TC15 for a TTT angle equal to $45^{\circ}$, in which the 3 dFIAT prediction is higher than the data after $60 \mathrm{sec}$. The maximum difference reaches around $60^{\circ} \mathrm{K}$ at around $140 \mathrm{sec}$. Figure 13 shows the temperature history of TC15 for various TTT directions. TC15 is located at about $3.0 \mathrm{~cm}$ from the initial stagnation point. The computation did not catch the temperature rise that appears in the first $40 \mathrm{sec}$ of the test. This early temperature rise has been seen in other carbonphenolic materials. However, the cause of this phenomenon is still not clear. The predictions indicate that increasing the TTT angle should increase the temperature at the location of TC15. Predictions and data agree well except that for the TTT angle equal to $45^{\circ}$. It appears that the TC15 temperature reading for angle of $45^{\circ}$ is in error, because its temperature reading ran below that of $\alpha=0^{\circ}$ after $140 \mathrm{sec}$.

The temperature contours of the front surface and the plane of symmetry at time equal to $400 \mathrm{sec}$ are shown in Figs. 14 a to $14 \mathrm{~d}$. For TTT angles equal to $45^{\circ}$ and $70^{\circ}$, the temperature at the lower half of the front surface clearly is higher than that at the upper half. This result is obtained because the carbon fiber orientation makes the upper corner cool down more effectively than the lower corner. At angle equal to $45^{\circ}$, the upper half front surface and the lower half front surface have the greatest temperature difference. For TTT angle of $90^{\circ}$, the TTT direction is parallel to the $\mathrm{y}$ axis, and thus the temperature contours of the lower half and the upper half are symmetric to the $\mathrm{x}-\mathrm{z}$ plane (horizontal surface). The temperature distributions of the right half and the left half are also symmetric because of the geometry symmetry. However, the temperature contours are not symmetric to the axis of symmetry (x axis).

Table III: The locations of thermocouples for Group II

\begin{tabular}{|c|c|c|c|c|}
\hline \hline Group II, TTT angle & $0^{\mathbf{0}}$ & $45^{\circ}$ & $70^{\circ}$ & $90^{\circ}$ \\
\hline & Depth $(\mathrm{cm})$ & & & \\
\hline TC11 & 0.59 & 0.61 & 0.63 & 0.62 \\
\hline TC12 & 1.04 & 0.97 & 1.00 & 1.00 \\
\hline TC13 & 1.41 & 1.38 & 1.37 & 1.38 \\
\hline TC14 & 1.80 & 1.74 & 1.76 & 1.75 \\
\hline TC15 & 3.04 & 3.02 & 3.03 & 3.04 \\
\hline \hline
\end{tabular}

\section{Conclusions}

A code validation study for new capabilities added to 3dFIAT was performed. These expanded capabilities include a multi-block moving grid system and an orthotropic thermal conductivity model. This paper focuses on conditions with surface recession but without significant shape change such that the fluid/solid coupling is not required. Two groups of test cases of 3dFIAT analyses for PICA model in an arc-jet stream were presented. In the first group, an axisymmetric iso-q shaped model was studied to check if three-dimensional multi-block moving grid system was properly implemented. A three-block no-singular-line grid system was used in this simulation. The agreement between 3dFIAT prediction and data was excellent for both the centerline and off-the-centerline thermocouples. In the second group, similar PICA models with various Through-The-Thickness (TTT) conductivity directions $\left(0^{\circ}, 45^{\circ}, 70^{\circ}\right.$, and $\left.90^{\circ}\right)$ were examined to check the implementation of orthotropic thermal conductivity model. Predictions from 3dFIAT were presented and also compared with arc-jet data. The difference on total surface recession between prediction and measurement is within 6\%. The 3dFIAT predictions agreed well with the thermocouple data for all the TTT angles. It was found that the thermocouple temperature reading from TC15 for TTT angle equal to $45^{\circ}$ was inconsistent with the readings from the rest of TTT angles, and was lower than the prediction by $3 \mathrm{dFIAT}$. 


\section{Acknowledgements}

This work was funded by the NASA Engineering and Safety Center (NESC) and by the Fundamental Aeronautics Program Hypersonics Project. The authors thank Dr. Parul Agrawal and Mr. Mike Olson for arcjet test data. The support from NASA Ames Space Technology Division through contract NNA04BC25C to ELORET Corporation is gratefully acknowledged. We also acknowledge NASA-SCAP for their critical financial support of the arcjet operational capability at Ames Research Center.

\section{References}

${ }^{1}$ Chen, Y.-K., and Milos, F.S., "Ablation and Thermal Analysis Program for Spacecraft Heatshield Analysis," Journal of Spacecraft and Rockets, Vol. 36, No. 3, 1999, pp. 475-483.

${ }^{2}$ Chen, Y.-K., and Milos, F.S., "Two-Dimensional Implicit Thermal Response and Ablation Program for Charring Materials," Journal of Spacecraft and Rockets, Vol. 38, No. 4, 2001, pp. 473-481.

${ }^{3}$ Chen, Y.-K., and Milos, F.S., "Three-Dimensional Ablation and Thermal Response Simulation System," AIAA Paper 2005-5064, June 2005.

${ }^{4}$ Anon., Users Manual, MARC Analysis Research Corporation, Volume A: Users Information, MARC Analysis Research Corporation, Palo Alto, CA, 1994.

${ }^{5}$ Milos, F.S., and Chen, Y.-K., "Ablation and Thermal Response Property Model Validation for Phenolic Impregnated Carbon Ablator," AIAA Paper 2009-262. AIAA Aerospace Sciences Conference, January 2009.

${ }^{6}$ Squire, T. H., Milos, F. S., and Hartlieb, G. C., "Aerospace Material Property Database (TPSX)," Journal of Spacecraft and Rockets, Vol. 46, No. 3, 2009, pp. 733-736.

${ }^{7}$ Moyer, C.B., and Rindal, R.A., "An Analysis of the Coupled Chemically Reacting Boundary Layer and Charring Ablator, Part II, Finite Difference Solution for the In-Depth Response of Charring Materials Considering Surface Chemical and Energy Balances," NASA CR-1061, June 1968.

${ }^{8}$ Kendall, R.M., "An Analysis of the Coupled Chemically Reacting Boundary Layer and Charring Ablator, Part V, A General Approach to the Thermochemical Solution of Mixed Equilibrium-Non-equilibrium Homogeneous or Heterogeneous Systems," NASA CR-1064, June 1968.

${ }^{9}$ Milos, F.S., and Chen, Y.-K., "Comprehensive Model for Multi-Component Ablation Thermochemistry," AIAA Paper 97-0141, Jan. 1997.

${ }^{10}$ Kays, W.M., and Crawford, M.E., Convective Heat and Mass Transfer, 2nd Edition, McGraw-Hill, 1980, pp. 355-357.

${ }^{11}$ Chen, Y.-K., and Milos, F.S., "Loosely Coupled Simulation for Two-Dimensional Ablation and Shape Change," AIAA Paper 2008-3802, June 2008.

${ }^{12}$ Wright, M. J., Candler, G. V., and Bose, D., "Data-Parallel Line Relaxation Method for the Navier-Stokes Equations," AIAA Journal, Vol. 36, No. 9, Sept. 1998, pp 1603-1609. 


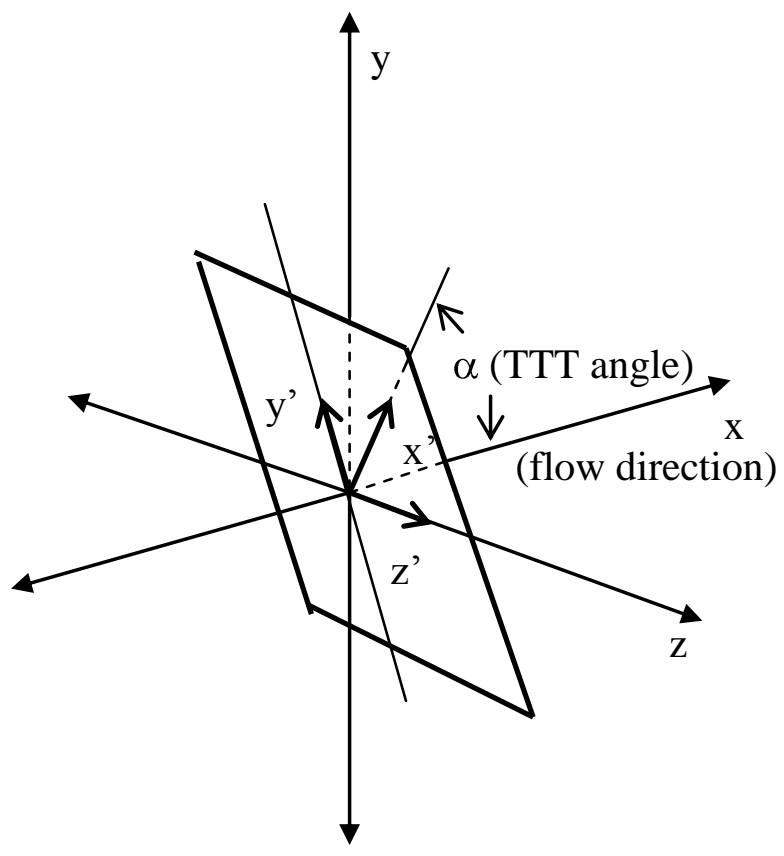

Figure 1. Local coordinate system $(x, y, z)$ and principle directions of conductivity ( $\left.x^{\prime}, y^{\prime}, z^{\prime}\right)$.

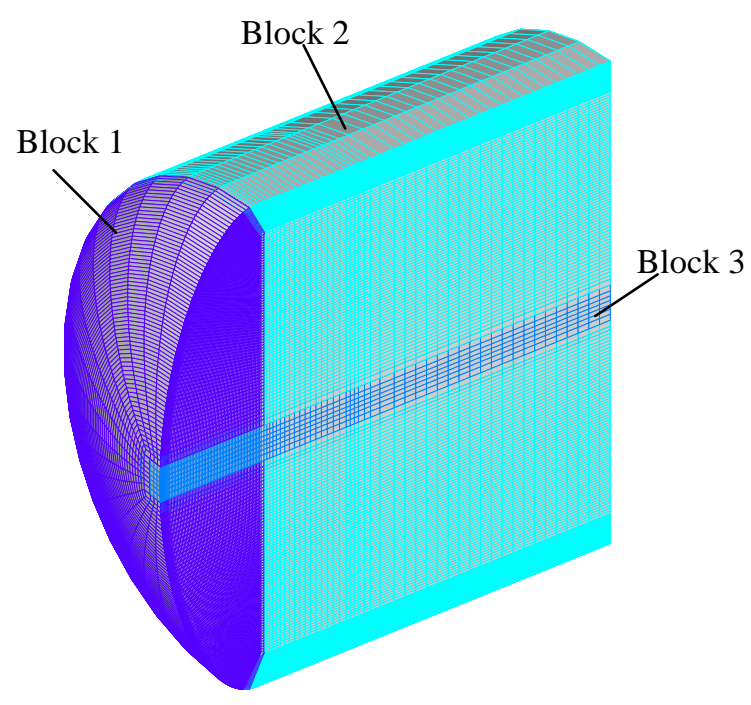

Figure 3. Three-block grid system for group I.

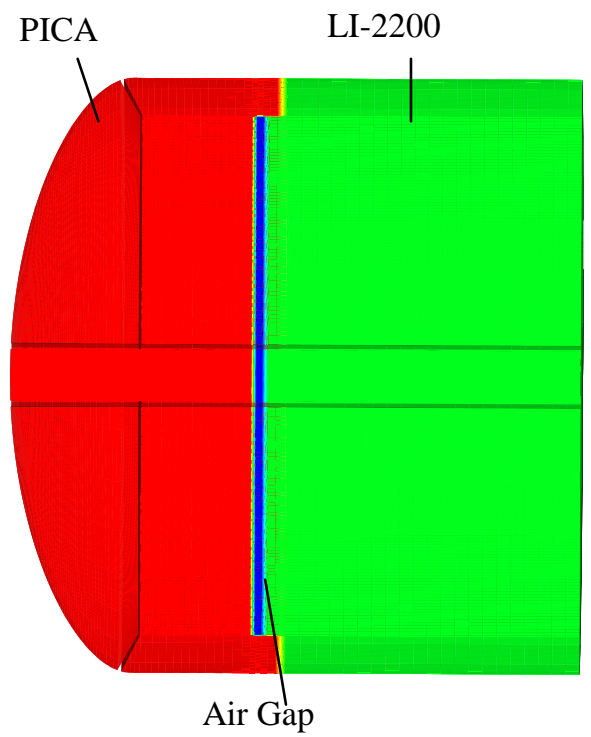

Figure 2. Material map for group I.

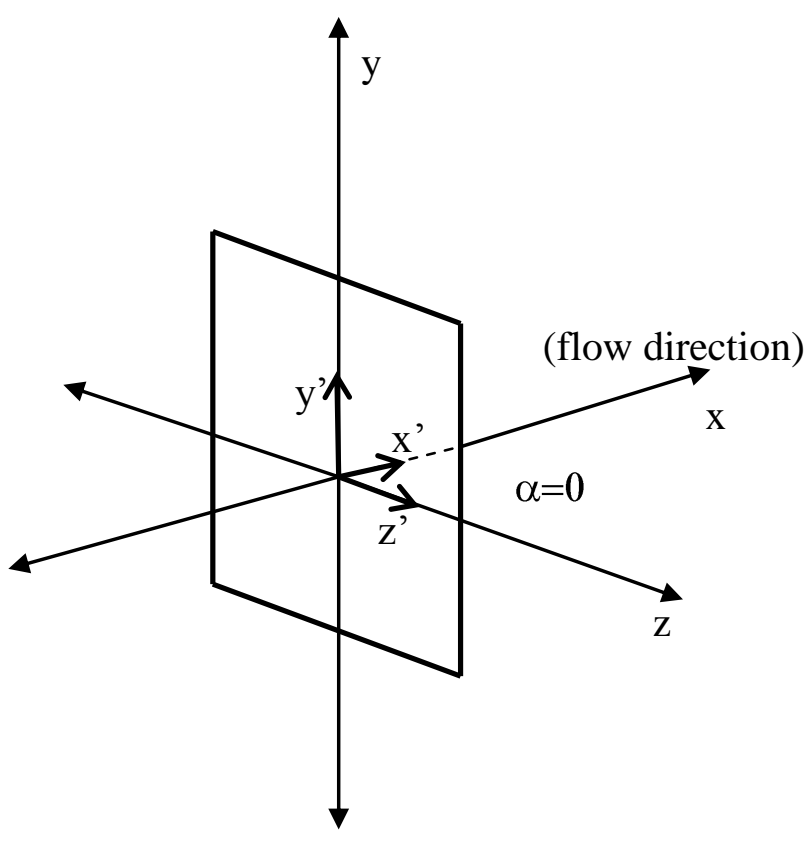

Figure 4. Coordinate systems for group I. 


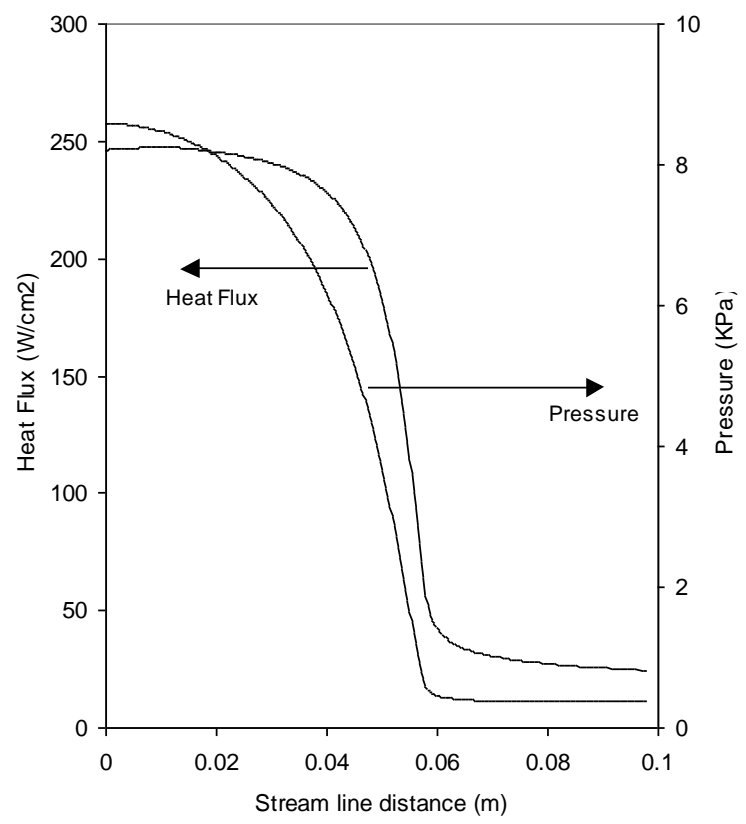

Figure 5. Surface heating and pressure profiles for Case $1 \mathrm{Ga}$.

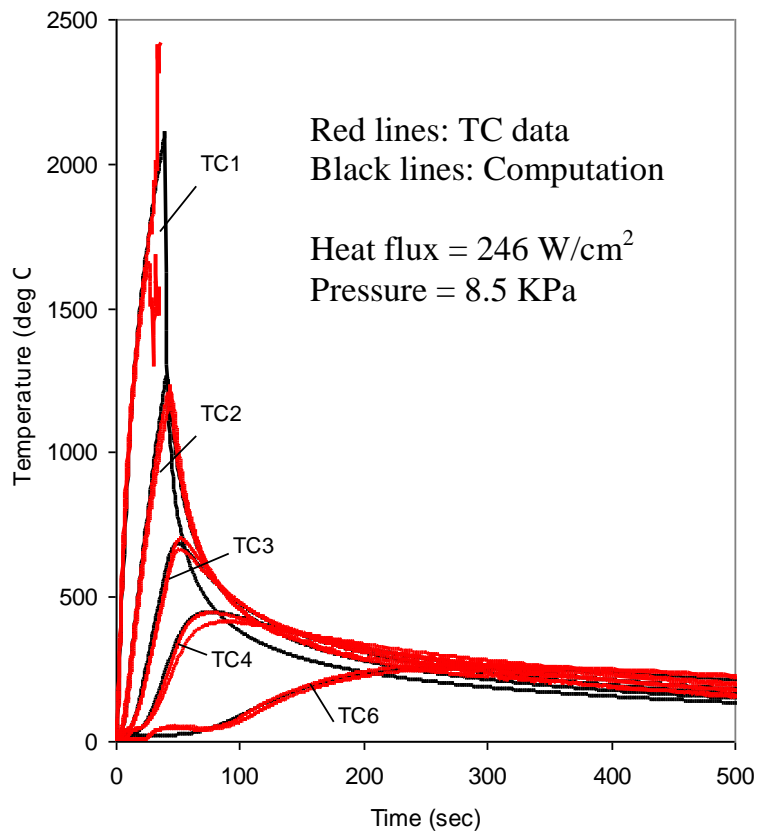

Figure 6a. Predictions vs. data along model centerline, Case G1a.

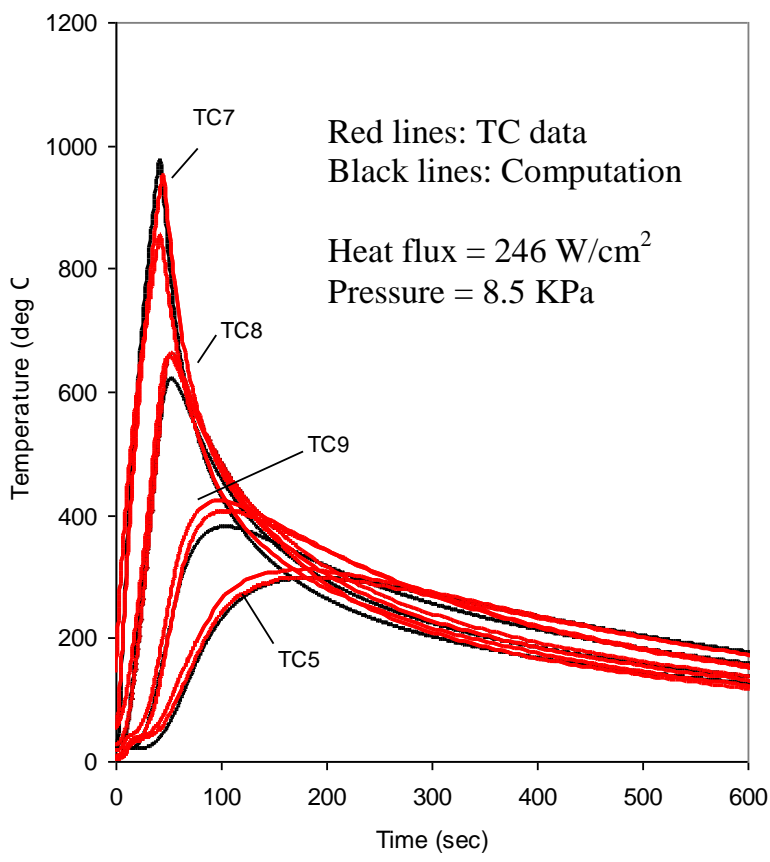

Figure 6b. Predictions vs. data moving outward from model centerline at $\mathbf{2 . 2 9} \mathrm{cm}$ depth, Case G1a.

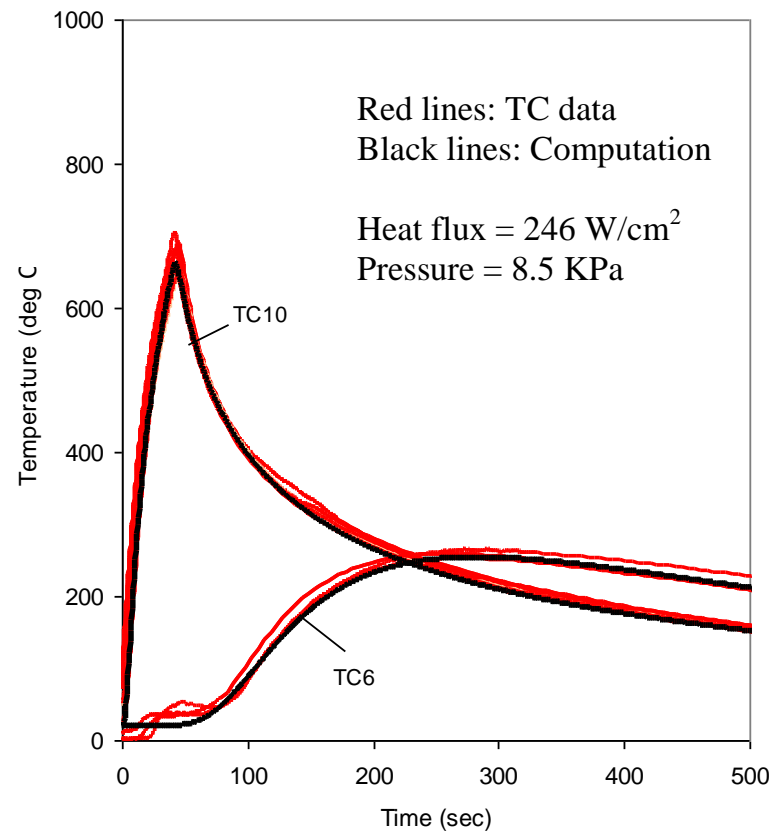

Figure 6c. Predictions vs. data moving outward from model centerline at $3.05 \mathrm{~cm}$ depth, Case G1a. 


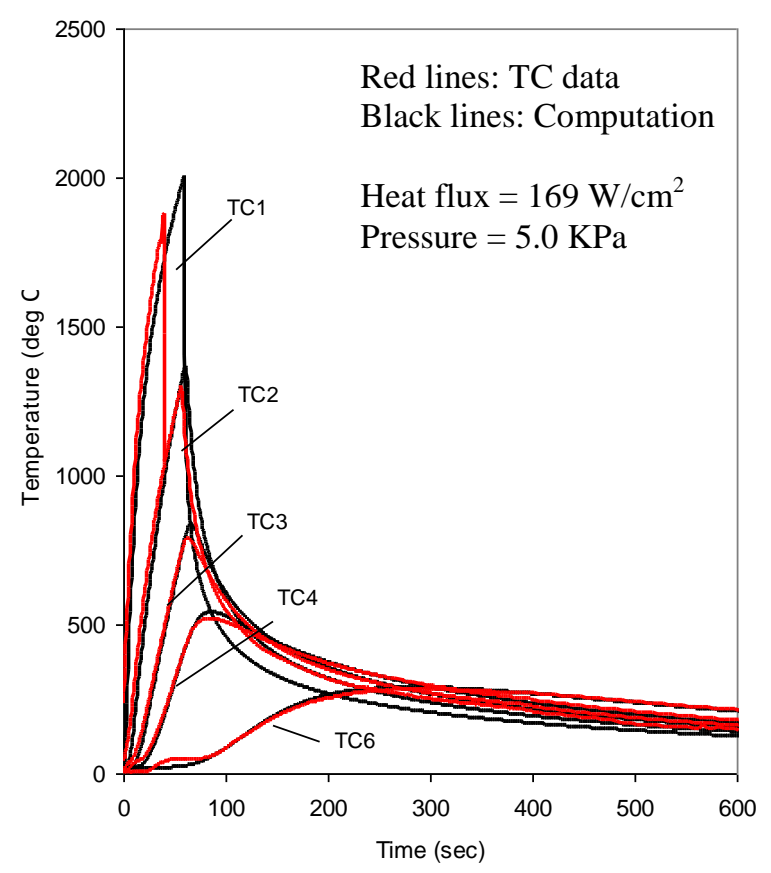

Figure 7a. Predictions vs. data along model centerline, Case G1b.

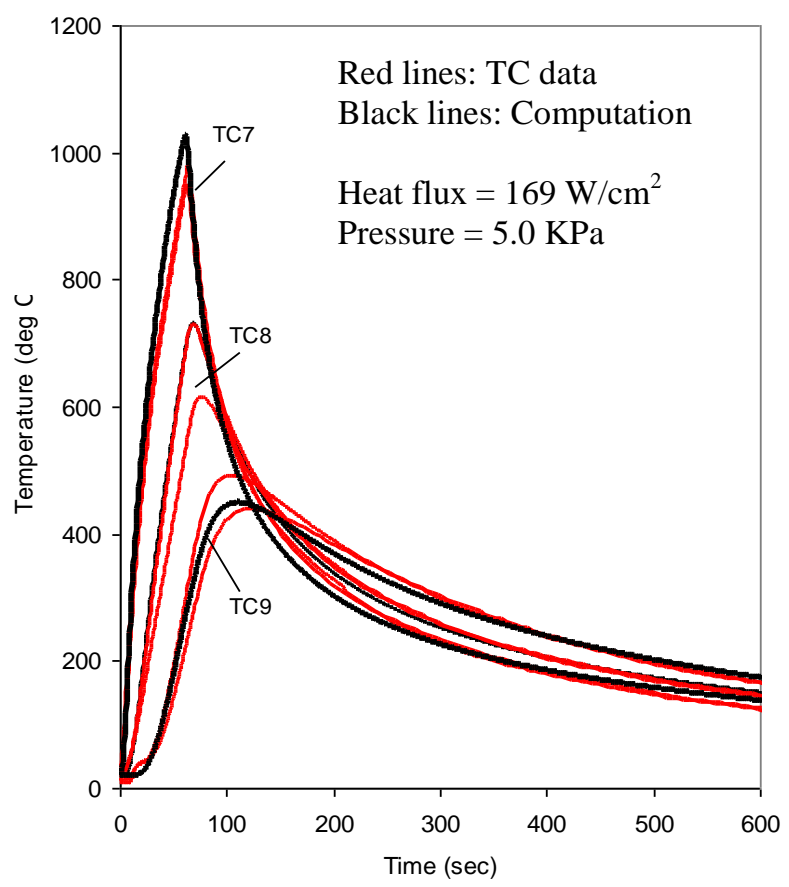

Figure 7b. Predictions vs. data moving outward from model centerline at $2.29 \mathrm{~cm}$ depth, Case G1b.

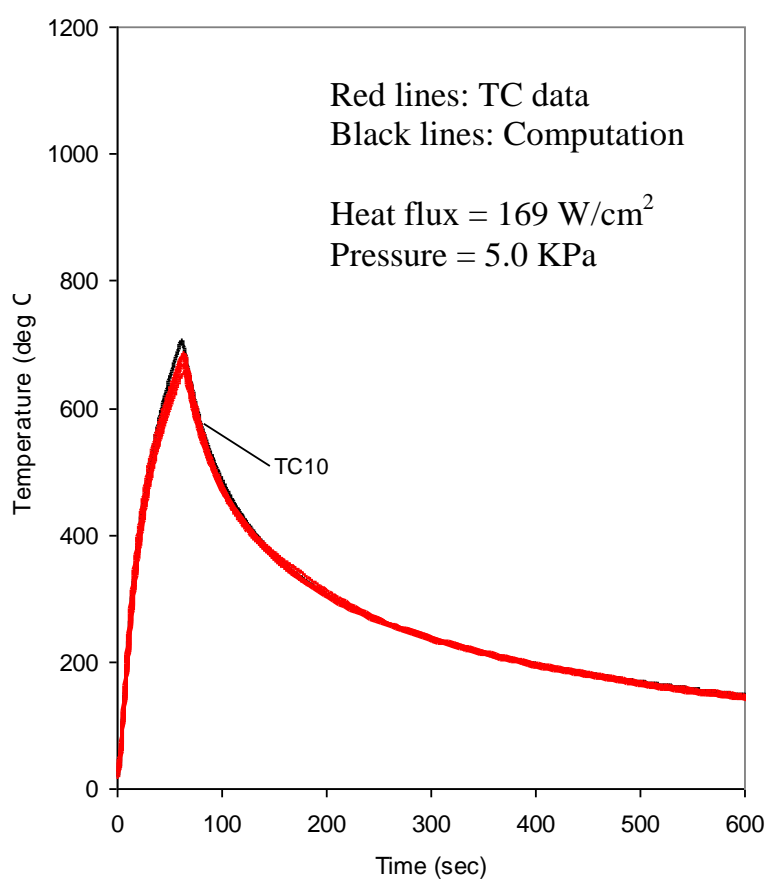

Figure 7c. Predictions vs. data moving outward from model centerline at $3.04 \mathrm{~cm}$ depth, Case G1b.

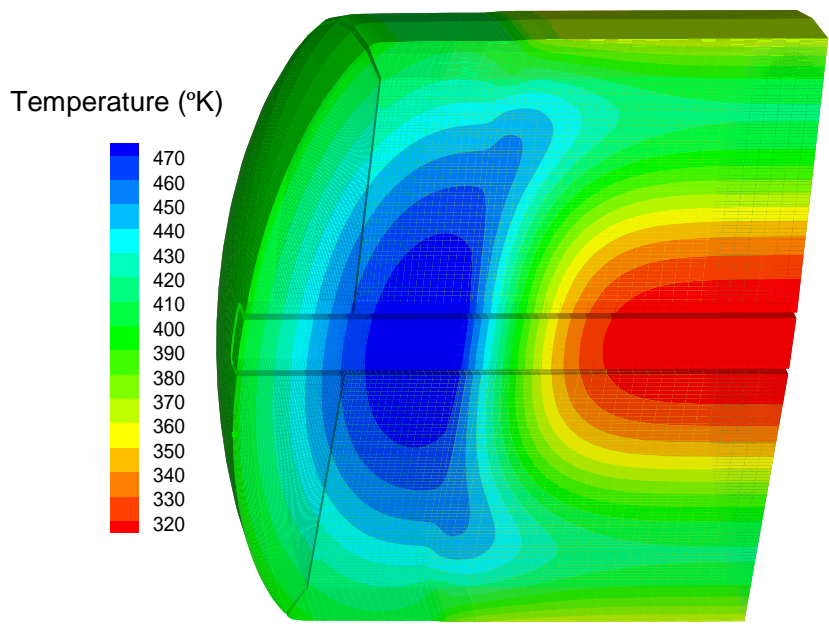

Figure 8. Temperature contours at the plane of symmetry at time $=600 \mathrm{~s}$. 


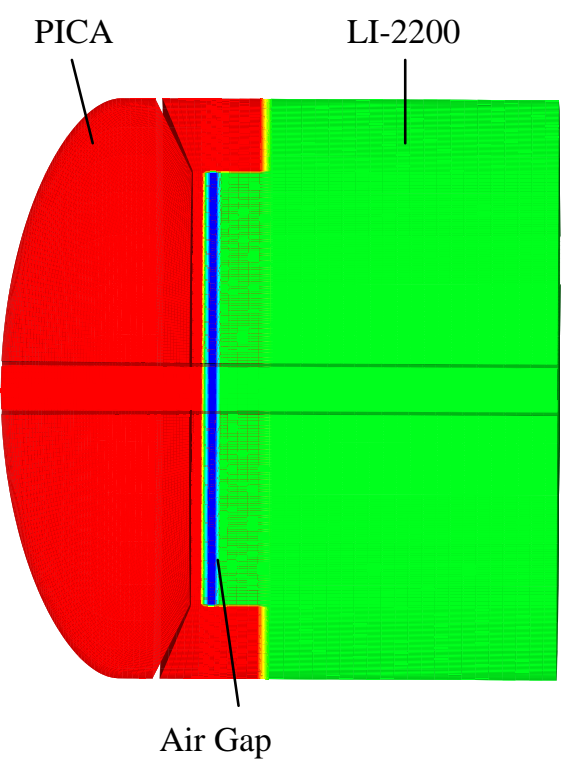

Figure 9, Material map for Group II.

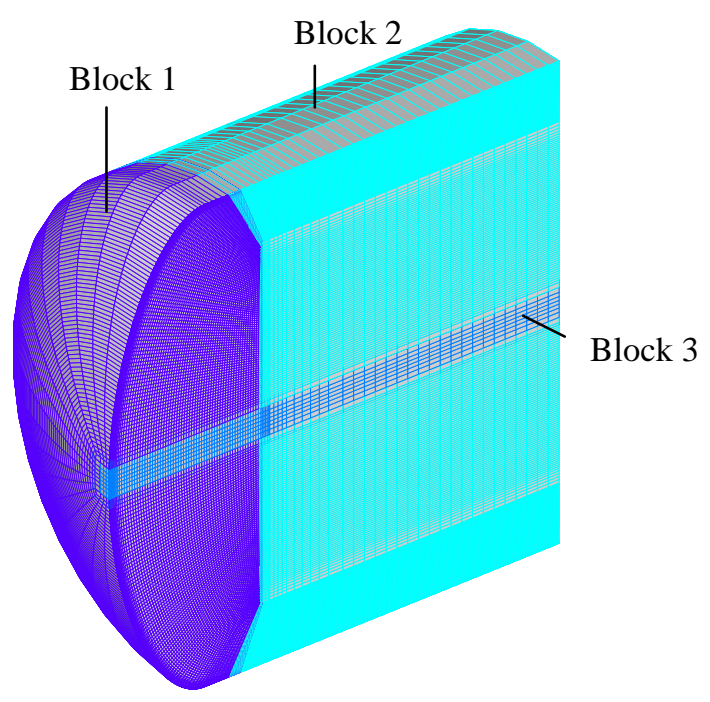

Figure 10. Three-block system for Group II.

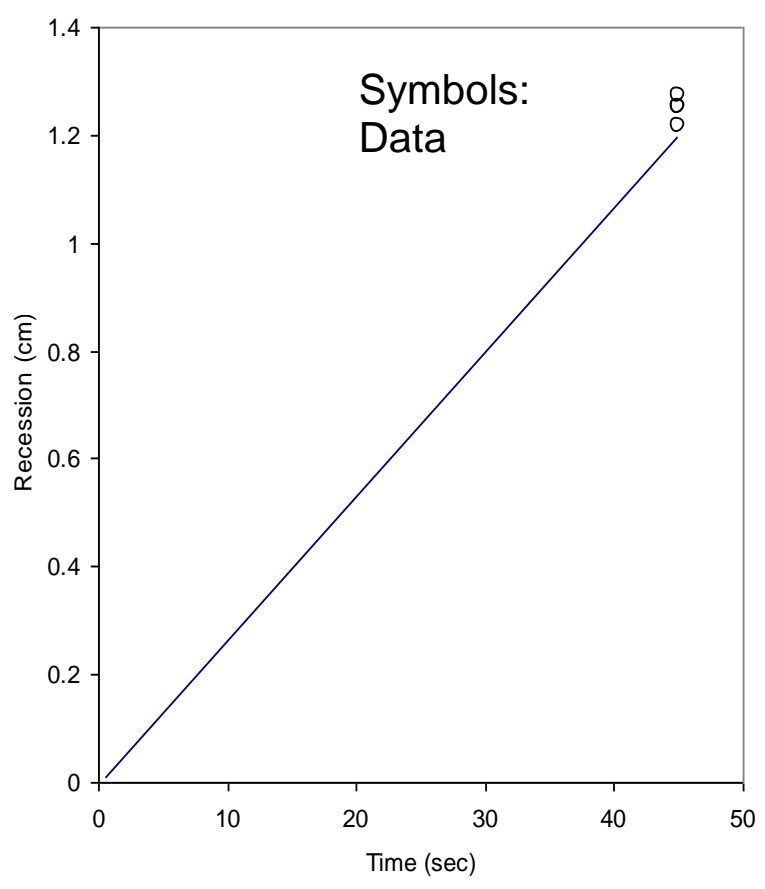

Figure 11. Stagnation point recession.

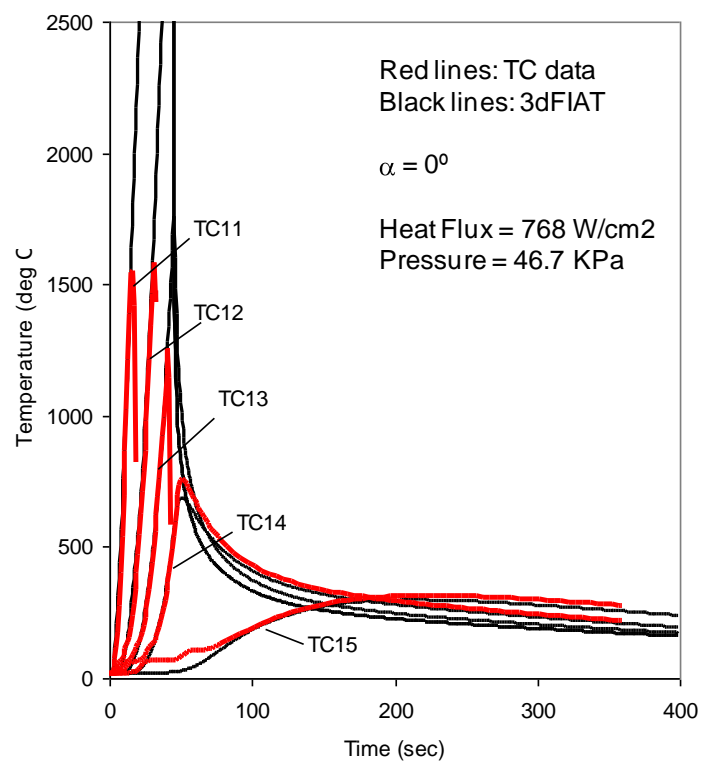

Figure 12a. Prediction vs. data along model centerline; $\alpha=0$, Case G2. 


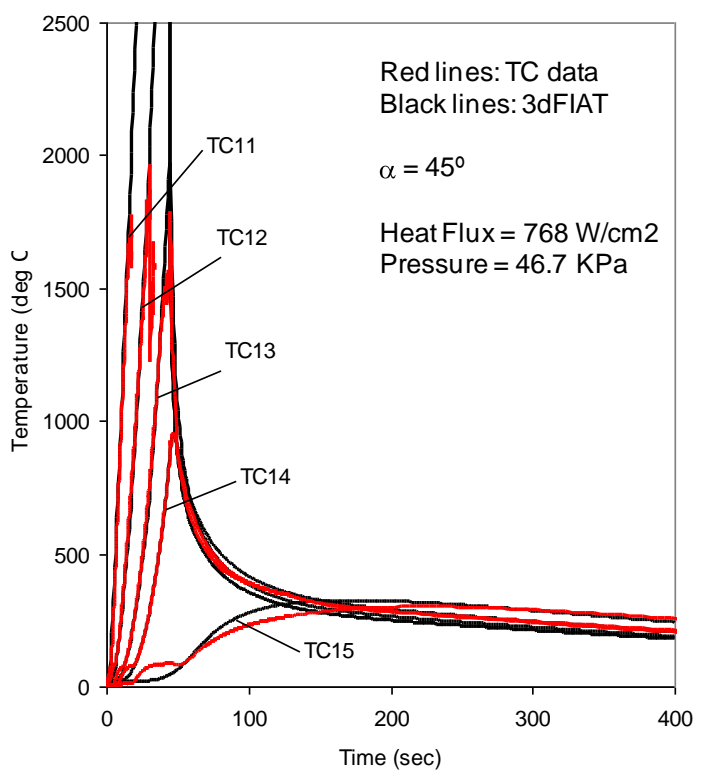

Figure 12b. Prediction vs. data along model centerline; $\alpha=45$, Case G2.

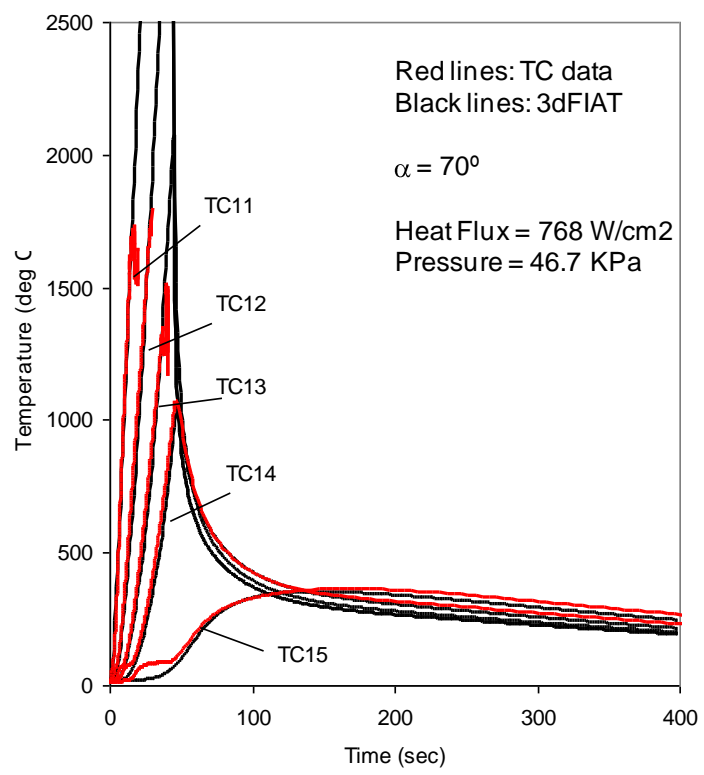

Figure 12c. Prediction vs. data along model centerline; $\mathbf{a}=\mathbf{7 0}$, Case G2

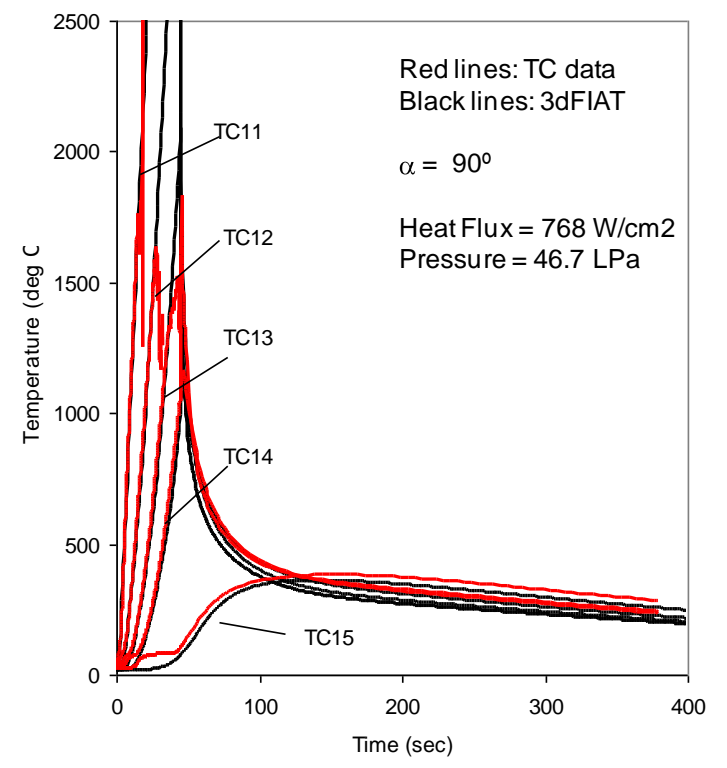

Fige 12d. Prediction vs. data along model centerline; $\alpha=$ 90, Case G2.

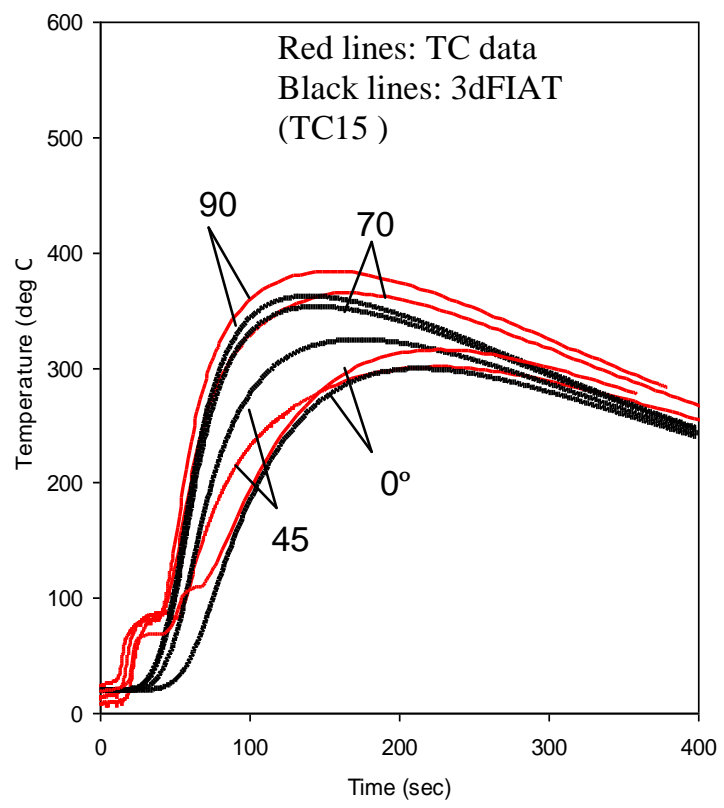

Figure 13. Comparison of temperature history at TC15. 


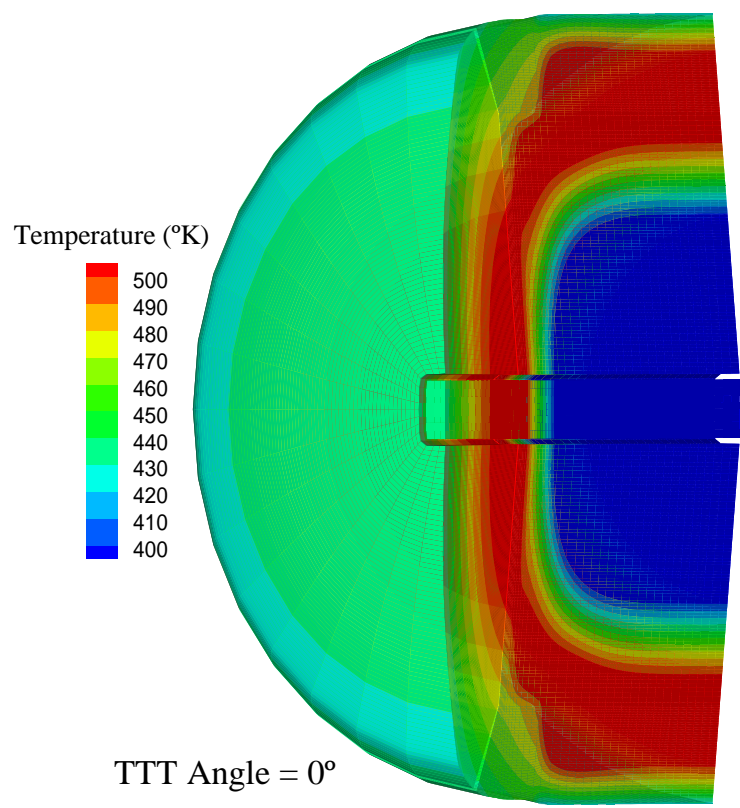

Figure 14a. Temperature contours at time $=400 \mathrm{~s}$.

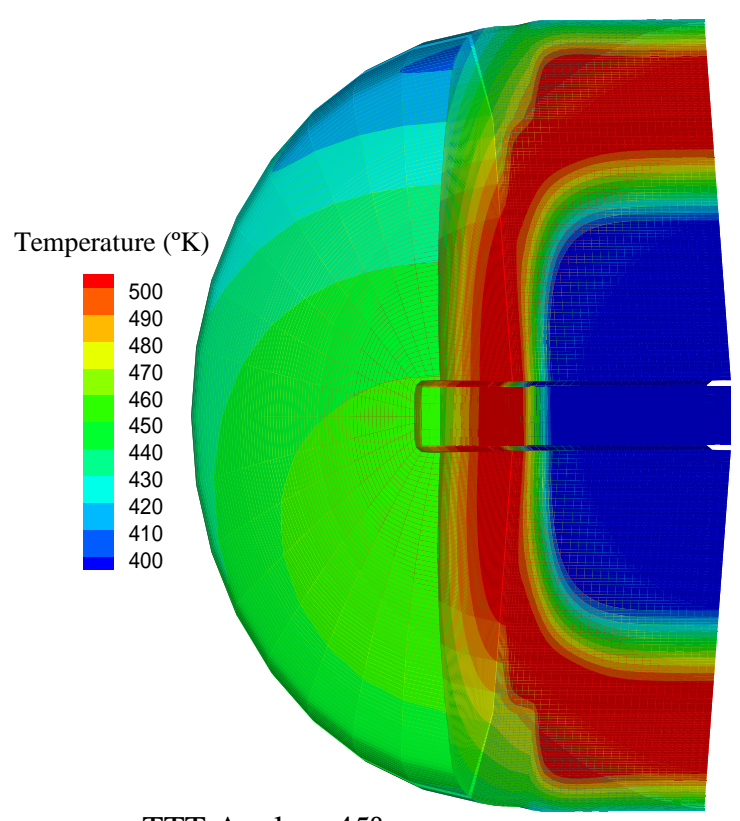

TTT Angle $=45^{\circ}$

Figure 14b. Temperature contours at time $=400 \mathrm{~s}$.

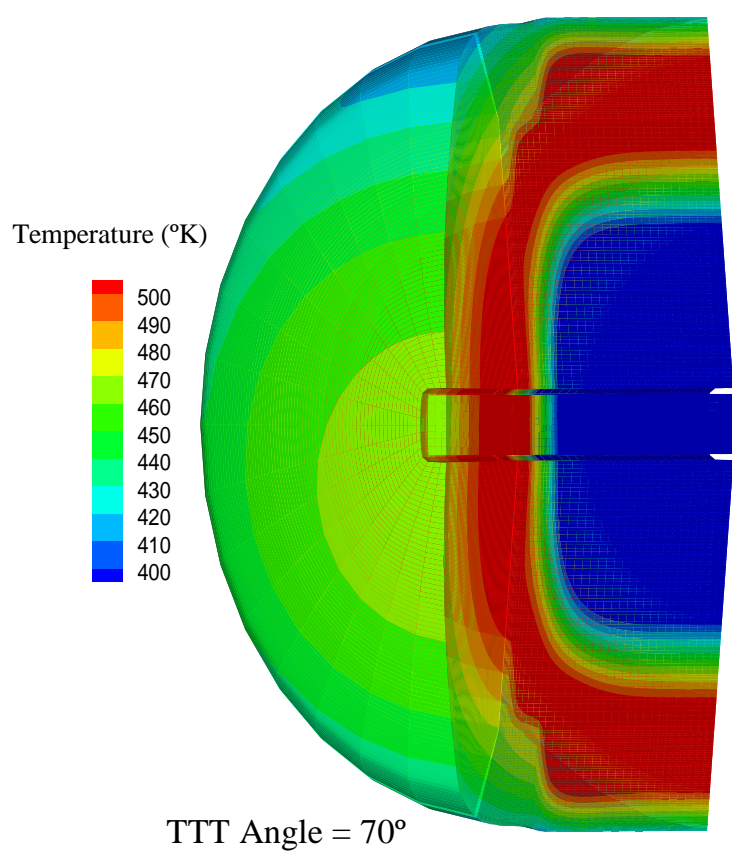

Figure 14c. Temperature contours at time $=400 \mathrm{~s}$.

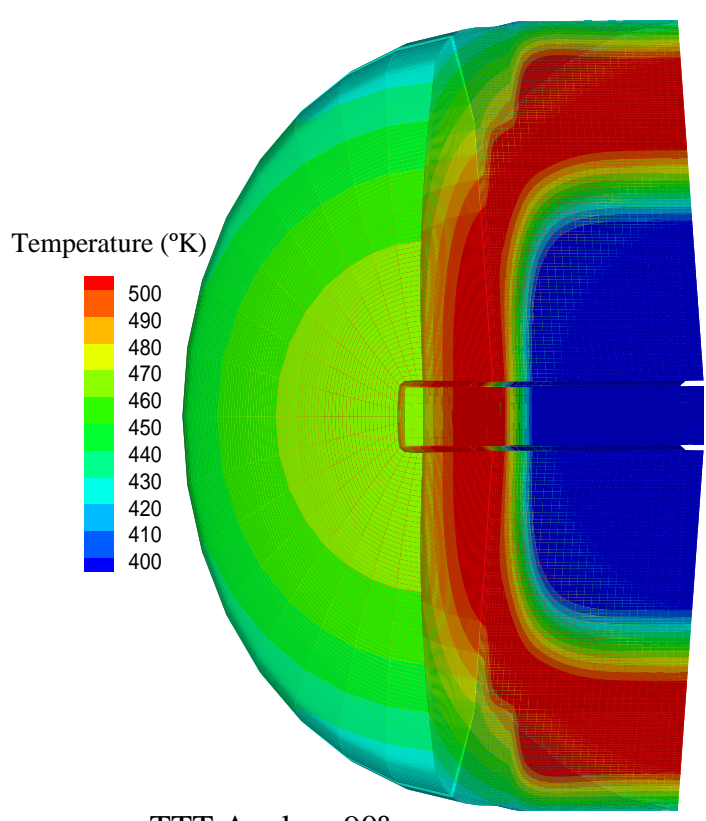

TTT Angle $=90^{\circ}$

Figure 14d. Temperature contours at time $=400 \mathrm{~s}$. 